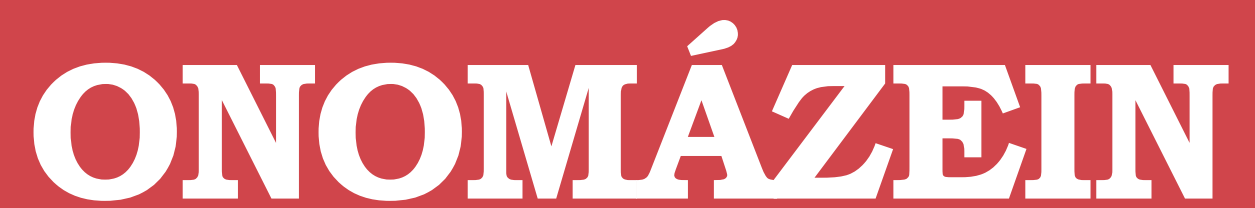

Revista semestral de lingüística, filología y traducción
PONTIFICIA UNIVERSIDAD CATÓLICA DE CHILE FACULTAD DE LETRAS

\title{
Medios semióticos y definiciones multimodales en las clases de Ciencias Naturales y Ciencias Sociales en una escuela para jóvenes sordos ${ }^{1}$
}

Semiotic media and multimodal reports in Natural science and Social Science in a school for deaf students

\section{Dominique Manghi Haquin \\ Pontificia Universidad \\ Católica de Valparaíso \\ chile}

\section{Oriana Illanes Pérez}

Pontificia Universidad

Católica de Valparaíso

chile

\section{Maritza Arancibia Pastene}

Pontificia Universidad

Católica de Valparaíso

chile

\section{Pía Herrera Letelier}

Pontificia Universidad

Católica de Valparaíso

Chile

\section{María Francisca Zamora S.}

Pontificia Universidad

Católica de Valparaíso

chile

ONOMÁZEIN Número Especial IX ALSFAL (2014): 37-56

DOI: 10.7764/onomazein.alsfal.2

\section{(c) $($ i) $\ominus$}

Dominique Manghi Haquin: Escuela de Pedagogía, Pontificia Universidad Católica de Valparaíso, Chile. Correo electrónico: dominique.manghi@ucv.cl

Maritza Arancibia Pastene: Escuela de Pedagogía, Pontificia Universidad Católica de Valparaíso, Chile. Correo electrónico: antho_04@hotmail.es

Oriana Illanes Pérez: Escuela de Pedagogía, Pontificia Universidad Católica de Valparaíso, Chile. Correo electrónico: esperanza.illanes@gmail.com

Pía Herrera Letelier: Escuela de Pedagogía, Pontificia Universidad Católica de Valparaíso, Chile. Correo electrónico: pia.edi@gmail.com

María Francisca Zamora S.: Escuela de Pedagogía, Pontificia Universidad Católica de Valparaíso, Chile. Correo electrónico: francisk_z@hotmail.com 


\section{Resumen}

La interacción en el aula es un fenómeno muy complejo y abordarlo desde la multimodalidad enriquece la forma de entender el panorama comunicativo entre profesores y aprendices. Esta perspectiva resulta esencial para describir lo que ocurre en un aula de estudiantes sordos y comprender el potencial semiótico de los recursos que se utilizan para enseñar y para aprender cuando el principal medio de intercambio de significados es el visual. La presente investigación es parte de un estudio mayor sobre alfabetización semiótica y su mediación en aulas escolares chilenas (Fondecyt 1130684), y tiene por objetivo la descripción multimodal de los géneros, medios y modos semióticos utilizados por dos docentes especialistas, uno de Ciencias Naturales y otro de Ciencias
Sociales, con su grupo de estudiantes sordos de $8^{\circ}$ año básico. A partir de la observación del desarrollo de una unidad didáctica se lleva a cabo un análisis multimodal del discurso. Entre los hallazgos destaca que los profesores estructuran sus clases en función del género definición, que despliegan a partir de interacción cara a cara mediante el uso de la lengua de señas junto con el uso de los medios pizarra, presentación computacional, software en línea, cuadernos y guías. En este estudio de caso, la definición funcionaría de manera visual para representar imágenes técnicas y las categorías también técnicas de la lengua dominante mediante la escritura continua y discontinua a estos jóvenes que conceptualizan el mundo desde la lógica visual de su lengua materna.

Palabras clave: multimodalidad; Lingüística Sistémico Funcional; educación de sordos; alfabetización multimodal; géneros multimodales.

\section{Abstract}

Classroom interaction is a very complex phenomenon and an approach from multimodality enriches the understanding of the communicative landscape between teachers and learners. This perspective is essential to describe what happens in a classroom of deaf students and to understand the semiotic potential of the resources used to teach and learn when visual semiosis is the primary media for the exchange of meaning. This research is part of a larger study on literacy and semiotic mediation in Chilean school classrooms (Fondecyt 1130684) and aims to the multimodal description of genres, semiotic media and modes used by two teachers, one of Natural Sciences and the other of Social Sciences, interacting with a group of deaf students of 8th grade. A Multimodal Discourse Analysis was carried out upon the observation of a whole curricular unit. Among the findings, we highlight that both teachers structure their lessons mainly around one genre: definition (reports), co-deployed in face to face interaction by using sign language with the whiteboard, computer presentations, online software, notebooks and printed learning activities. In this case study, definitions work visually to represent both technical images and technical categories of the dominant language through continuous and discontinuous writing for these young deaf students to conceptualize the world from the visual logic of their first language.

Keywords: multimodality; Systemic Functional Linguistics; deaf education; multimodal literacy; multimodal genre. 


\section{Introducción}

El análisis del discurso es un campo fértil para conocer tanto los significados en contexto como los recursos utilizados para la semiosis, ampliando la comprensión respecto del fenómeno discursivo. Para abordar la interacción en el aula los analistas se enfrentan a un panorama comunicativo muy complejo, ya que no solo se crea significado a partir de los recursos lingüísticos, sino mediante otros de distinta naturaleza, entre ellos los visuales. El enfoque multimodal pone énfasis en todos los modos semióticos que aportan a la construcción de significado (Kress, 2010) y ofrece una mirada más amplia para observar la semiosis en el aula. Esta perspectiva resulta esencial para describir lo que ocurre en la comunicación en un aula, más aún si las características de los estudiantes corresponden a una condición de sordera, en la cual la vía visual se transforma en el principal canal para acceder a la información que se intercambia. La descripción multimodal puede aportar para comprender el potencial semiótico de los recursos que se utilizan para enseñar y para aprender en clases.

Desde la Semiótica Social los recursos semióticos y sus características responden a las necesidades dinámicas de las comunidades que crean significados con ellos (Hodge y Kress, 1988; Van Leeuwen, 2005), y quienes se comunican optan por determinados recursos - géneros, medios y modos - según sus propósitos sociales y según las características semióticas y materiales de su entorno (Halliday, 1982; Kress, 2010). Esto es válido tanto para la lengua de señas como sistema convencional de signos como para los demás recursos semióticos prototípicos del aula escolar, incluidos aquellos de naturaleza visual.

En el contexto escolar, definiciones (reports) y explicaciones son muy frecuentes en la enseñanza de la historia y de la biología, ya que a través de ellas los profesores representan para sus estudiantes la manera en que esperan que entiendan el mundo social y natural, respectivamente. Estos géneros son textualizados por los profesores de manera multimodal, combinando interacción cara a cara con uso de pizarrón (Manghi, 2013) para representar significados tipológicos y topológicos (Lemke, 1998).

Por este motivo, interesa explorar el potencial para construir significados de las definiciones desplegadas visualmente por los profesores a través de distintos medios semióticos prototípicos de la sala de clases, dirigidos, en este caso, a estudiantes cuyo principal canal de aprendizaje es el visual. La presente investigación es parte de un estudio mayor sobre alfabetización semiótica y su mediación en el aula escolar (Fondecyt 1130684) y tiene por objetivo la descripción multimodal de los géneros, medios y modos semióticos utilizados por dos docentes especialistas: uno en Ciencias Naturales y otro en Ciencias Sociales, para mediar el aprendizaje de su grupo de estudiantes sordos de $8^{\circ}$ año básico.

A continuación se presenta el marco teórico que sustenta esta investigación, la Semiótica Social y la multimodalidad, así como algunas características de las personas sordas y su aprendizaje. Luego se sintetiza la metodología usada para la descripción de medios y modos semióticos, y se presentan los principales hallazgos que giran en torno al género que destaca en el corpus: las definiciones multimodales.

\section{El enfoque multimodal en el aula}

El estudio del discurso en el aula ya constituye una tradición entre las investigaciones de la lingüística aplicada a la educación. Recientemente, Lemke (1998) y el equipo de Kress han aportado una nueva mirada considerando el discurso en el aula como un discurso multimodal, es decir, un discurso en el cual los significados se construyen no solo a partir del lenguaje, sino en base a múltiples recursos semióticos que se entrelazan en las interacciones entre profesor y estudiantes en un aula escolar. Si bien Mercer (2010) y Christie (2002) indican que el discurso lingüístico sigue siendo el recurso privilegiado para el desarrollo de la clase, el aporte de la mira- 
da multimodal ayuda a revelar el valor semiótico de cada uno de los recursos que se entrelazan en el discurso del aula, distinguiendo entre las funciones que cumple cada uno de ellos para el aprendizaje y para la enseñanza.

La aproximación multimodal requiere poner atención en el despliegue de significados que se llevan a cabo en el contexto del aula, a partir de los múltiples modos utilizados y la forma en que son orquestados en la configuración del discurso escolar (Kress y Van Leeuwen, 2001).

En este sentido, podemos referirnos a una alfabetización multimodal relacionada con el aprendizaje de la diversidad de formas de representar y comunicar en el panorama semiótico y discursivo contemporáneo (New London Group, 1996). Este enfoque pone de manifiesto que las formas de representar y comunicar son prácticas sociales (Van Leeuwen, 2005) y como tales cambian en el tiempo de acuerdo a las necesidades de los grupos sociales (Hodge y Kress, 1988), entre ellas las necesidades del contexto escolar. El impacto de las nuevas tecnologías ha influido tanto en los medios impresos (libros, cuadernos, pizarra, guías de trabajo, libros de texto o manuales, entre otros) como en los medios digitales (juegos computacionales, software educativos, páginas web, presentaciones computacionales, entre otros) más allá del contexto escolar, ofreciendo múltiples potencialidades innovadoras de crear significado a partir de la combinación de una variedad de recursos semióticos (Kress, 2010). Este panorama complejo, que combina lo impreso y digital en la interacción cara a cara prototípica del aula escolar, corresponde al paisaje comunicativo a partir del cual los niños y jóvenes de hoy aprenden, y nos desafía para observar cómo comprenden y producen textos para estos ambientes de aprendizaje.

En este estudio, alfabetizarse implica el acceso, comprensión y producción creativa de las convenciones para significar, siempre considerando que el uso de ellas varía de acuerdo a los aspectos sociales y contextuales así como tam- bién materiales del entorno, en cuanto a los medios y modos disponibles para la semiosis (Kress, 2010). En la etapa escolar el aprendiz amplía de manera importante las formas de representación vernáculas, comenzando a pertenecer a las diversas comunidades y culturas y enriqueciendo su identidad (Álvarez y del Río, 2003). Cada conjunto de saberes, relacionados con determinadas disciplinas y sus tradiciones, requiere que el estudiante aprenda a ver el mundo como lo hace esa tradición, a razonar, comunicarse y actuar de una manera particular (Veel, 1997).

Es entonces esta forma de aprendizaje semiótico la que - a lo largo de la trayectoria escolar - se torna una alfabetización cada vez más avanzada. Aprender involucra de manera central la participación en actividades sociales en las cuales es necesario apropiarse de las herramientas culturales y sistemas semióticos (Rogoff, 1990), coherentemente con el enfoque de la psicología sociohistórica vigotskiana, que pone en un lugar central del desarrollo humano al proceso de semiosis o creación de significado. La alfabetización semiótica o multimodal en la escuela, entendida como un tipo de alfabetización avanzada (Schleppegrell, 2004), requiere de una mediación intencionada para las especificidades que implica su aprendizaje.

\subsection{Semiosis: conocimiento, aprendices y mediación semiótica}

A partir de la idea de Chevallard (1997), quien nos plantea una relación entre el saber a enseñar, el aprendiz y el profesor, y pone el foco en la distancia entre el saber a enseñar y el saber tal como es enseñado por el profesor (trasposición didáctica), podemos tomar una perspectiva semiótica para describir estos tres elementos requeridos para la alfabetización avanzada. Reformularemos estos tres elementos con énfasis en la creación de significado: 1) los conocimientos a enseñar y a aprender (saber, saber hacer, saber ser) y las características epistemológicas que condicionan sus formas de representación 
y comunicación; 2) el potencial de desarrollo del aprendiz y sus características para la representación y comunicación; y 3) la mediación que realiza el profesor entre estos conocimientos incluyendo los recursos semióticos que seleccione como mediadores semióticos para enseñar a sus aprendices. A continuación desarrollamos estas tres ideas.

En primer lugar, respecto del conocimiento de las Ciencias Naturales (especialmente biología) y Ciencias Sociales (especialmente historia), corresponden a saberes alejados del saber cotidiano, los que Bernstein (2000) denomina conocimiento vertical o fuera del sentido común. Estos dos conjuntos de saberes provienen de tradiciones disciplinares diferentes, dos cosmovisiones especiales, una sobre el mundo natural y la otra sobre el social, que son producto de comunidades científicas que trasmiten sus formas de razonar, comunicar, actuar y valorar, todos saberes que requieren mediación de un experto para su aprendizaje. Por lo tanto, desde la Semiótica Social, los significados que se construyen en el discurso de la comunidad de la historia y de la biología, al igual que los otros discursos científicos, no corresponden a representaciones de conceptos dispuestos en la realidad, sino más bien a la interpretación de la experiencia humana de dicho grupo social (Halliday y Martin, 1993; Maton, 2013).

Respecto de la historia y Ciencias Sociales desde la Semiótica Social, estas son disciplinas interpretativas, y al ser ciencias sociales construyen y transmiten su conjunto de conocimientos de manera segmentada. Esto implica que en la historia coexisten varias teorías que explican lo mismo pero desde distintas interpretaciones, cada una con sus propios criterios (Maton, 2013). La representación de los eventos históricos - aquel conocimiento que se elige representary aquel que queda sin ser representado- es el resultado de la interpretación ideológica de quien construye el discurso (Martin, 2003; Oteíza, 2009; Barletta y Mizuno, 2011).
La disciplina se construye en base a tres dimensiones: la causalidad, la relación temporal-espacial y la evidencialidad (Oteíza, 2011). Desde esta perspectiva, aprender historia y Ciencias Sociales implica pensar, argumentar y comunicar sobre el mundo social desde estas dimensiones, es decir, de la manera como se hace en la disciplina (Veel, 1997).

Desde los aportes de la sociología del conocimiento, y la extensión del enfoque de Bernstein (2000) a través de la teoría del código de legitimación (Maton, 2013), el discurso de la historia se construye mediante opciones lingüísticas que favorecen presentar participantes como abstracciones. Este recurso semiótico posibilita manejar epistemológicamente el pasado y, además, pueden otorgar una carga axiológica que refleja la ideología de una perspectiva histórica u otra. Aprender esta mirada constituye un aprendizaje clave para ser un estudiante legitimado en educación secundaria (Martin, Maton y Matruglio, 2010; Oteíza, 2011).

En cambio, epistemológicamente los conocimientos de las Ciencias Naturales y biología corresponden a un cúmulo de conocimiento que, si bien también es interpretativo, se presenta de manera objetiva (Martin, 2003; Moss y Chamorro, 2011), ya que tiene por función social elaborar teorías, desafiar prácticas científicas y crear conocimiento nuevo (Veel, 1997).

Para esto, la forma de transmitir el conocimiento corresponde a una estructura jerárquica (Bernstein, 2000), es decir, hay una sola gran teoría que es aceptada por la comunidad sobre la cual se construyen los conocimientos nuevos a través de una organización jerárquica y de principios explícitos, coherentes y sistemáticos que buscan generalizar teorías que integren y expandan el conocimiento a otros fenómenos naturales (Maton, 2013).

Los ejes de esta disciplina y su forma particular de entender el mundo tienen que ver con la composición/descomposición y la clasificación/ 
subclasificación de los conceptos. Es el recurso lingüístico y su potencial de significado tipológico el que posibilita clasificar, analizar y construir taxonomías en torno a los conceptos, creando las teorías científicas (Veel, 1997; Lemke, 1998).

Entre las particularidades del discurso de las Ciencias Naturales destaca la representación del conocimiento a través de jerarquías taxonómicas de léxico técnico específico y el uso de ciertos recursos gramaticales, como grupos nominales muy complejos y cláusulas constituidas como relaciones de identificación o causa (La membrana plasmática es una bicapa lipídica cuya función es rodear, limitar, dar forma y contribuir a mantener el equilibrio entre el medio intracelular y el medio extracelular). De manera importante las nominalizaciones o metáforas gramaticales se ven reflejadas en el empleo de sustantivos abstractos derivados de verbos - precipitación, filtración- que presentan un significado como un participante en el mundo que tiene existencia fuera de la relación o verbo en el que realmente se da ese significado (Halliday y Martin, 1993). No sería posible razonar, comunicar, actuar de manera científica sin metáfora gramatical, ya que este recurso lexicogramatical permite un alto nivel de abstracción que impacta en la organización textual, y en las relaciones lógicas implícitas o construidas como metáfora lógica (Moyano, 2010). La densidad semántica de la ciencia depende de la metáfora gramatical, y los aprendices dependen de la escolarización para acceder a ese código y poder componer y descomponer, clasificar y subclasificar. Esto es lo que Martin (2013) denomina gramática poderosa (power grammar), que se da también en historia, pero con mayor fuerza en la biología.

En segundo lugar, respecto de las características de los escolares sordos y su aprendizaje en la reformulación semiótica propuesta del triángulo de Chevallard (1997), lo primero es indicar que en este estudio hemos optado por denominarlos sordos y no hipoacúsicos o personas con pérdida auditiva, ya que esto implica reconocer que pertenecen a una comunidad particular que se comunica a través de un sistema lingüístico de naturaleza visual: la lengua de señas chilena. En general, los estudios que abordan la complejidad de la interacción en el aula encuentran un profesor y sus estudiantes interactuando y comunicándose de manera tradicional: cara a cara, hablando y escuchándose a través del medio auditivo. Sin embargo, este estudio de caso describe la interacción entre un profesor oyente que maneja la lengua de señas como segunda lengua y su grupo de estudiantes, todos ellos sordos, quienes se comunican mediante la lengua de señas chilena. La sordera, desde la mirada socioantropológica, deja atrás el enfoque biomédico y ya no se considera como un déficit, sino como una condición o variable, y a la persona sorda, no como minusválida, sino como miembro de una minoría lingüística y social (Palacios, 2008).

La condición de sordera no es homogénea; existen diversos tipos y grados de sordera y diferentes factores presentados en distintas etapas del desarrollo de una persona que le dan origen, pero tienen en común que su comunicación y conocimiento del mundo ocurre de una manera particular. Por lo tanto, hay una diferencia en relación a cómo se produce el intercambio de significados en la población sorda y la oyente. Mientras que al ofrecer significados en la interacción los sordos signan para comunicarse, cuando comprenden y toman su turno en el intercambio requieren interpretar los movimientos del lenguaje signado y sus convenciones (Herrera, 2006). Por tanto, las características de aprendizaje en esta población - sus posibilidades de representación y comunicación de significados - se encuentran determinadas por la lengua empleada y el hecho de que la recepción de la información se fundamenta en el sentido de la visión. Tanto la lengua de señas como los demás recursos visuales empleados en los contextos pedagógicos entregan a las personas sordas la posibilidad de aprender y aprehender em- 
pleando los ojos, de igual manera que un oyente lo hace con sus oídos. De esta manera, cobra especial relevancia utilizar el enfoque multimodal para describir prácticas pedagógicas que toman estas características en consideración, entregando información principalmente por vía visual y utilizando estrategias visuales (imágenes, alfabeto dactilológico, lectura labial, entre otras) para aprovechar otros canales sensoriales.

En tercer lugar, respecto a la mediación del profesor y la selección de los recursos para enseñar, proponemos que el enfoque multimodal desde la Semiótica Social resulta una perspectiva adecuada para poner en un lugar relevante los elementos visuales utilizados en las prácticas pedagógicas dirigidas a un grupo de estudiantes sordos. En este estudio, el discurso del profesor tiene un sentido pedagógico, es decir, todos los recursos que selecciona para comunicarse con sus aprendices son interpretados con una función de enseñanza y formación de la identidad de los aprendices. Los planteamientos de Halliday (1982) señalan que los recursos utilizados por los seres humanos para la creación de significado corresponden a un proceso social que se lleva a cabo a través de una selección de opciones semióticas que se encuentran en una relación dialógica respecto del contexto. Dichas opciones conforman un texto que refleja el contexto pero que a la vez lo construye. Las opciones de los profesores entonces tienen que ver con el contexto y sus tres variables: campo, tenor y modo - concepto conocido como registro-. De esta manera, el discurso del aula refleja y construye el campo: el contenido curricular de Historia o de Biología; enactúa el tenor: Ia relación entre quienes participan y sus roles de profesor y estudiantes en esa cultura escolar; y se concreta en un tejido textual a partir de los modos para la interacción y los medios o tecnologías disponibles para crear significados.

En este estudio, nos enfocaremos en los medios presentes en el discurso en el aula como parte de las opciones del profesor para significar para sus aprendices. Los medios semióticos corresponden a las tecnologías producidas por la cultura humana, que poseen características materiales y sociales que se encuentran en una relación dialéctica con los posibles significados a crear. Es decir, un libro cuyo soporte material es el papel y que socialmente es utilizado para determinadas funciones ofrece un potencial para crear significado en el cual se pueden combinar fotografías, escritura y tipografía, mientras que un cuaderno, pese a que su soporte material es similar y ambos son impresos, socialmente cubre funciones distintas, y los significados usualmente creados se expresan a través de escritura, otra clase de tipografías y dibujos u otros modos visuales. Por otro lado, una presentación computacional, cuyo soporte es digital, socialmente ha sido diseñada para apoyar presentaciones orales y ofrece un potencial para construir significados no solo en base a elementos visuales como escritura y fotografías, sino también auditivos como música, grabaciones de voz, videos u otros, incluso hipervinculados a recursos de internet.

Desde la perspectiva multimodal, cualquier texto que significa a través de la interacción de más de un recurso puede ser definido como un texto multimodal, independientemente del medio -interacción cara a cara, impreso o electrónico - en el cual se distribuya. Cada modo semiótico participante en un texto solo representa parcialmente un significado (Lemke, 1998); el significado completo corresponde a la interacción de la totalidad de modos usados simultáneamente en el texto (O'Halloran, 2011). Es decir, en un texto estático construido en base a lengua escrita y una foto, como frecuentemente observamos en los manuales escolares, tanto escritura como fotografía aportan significados parciales y, por lo tanto, para aprehender el significado completo representado allí hay que integrar los aportes de ambos recursos.

Los potenciales de cada modo semiótico son incomparables entre sí y se relacionan tanto con la materialidad del medio como con los 
usos estabilizados de acuerdo a las necesidades de cada comunidad (Kress y Van Leeuwen, 2001; Kress, 2010), como también con sus posibles usos futuros (Jewitt, 2011). Por ejemplo, un mapa en papel o en pantalla representa a través de las convenciones de la disciplina geográfica la espacialidad, contigüidad, ubicación, proporciones entre elementos, etc., representadas de manera eficiente a través de los modos colores, líneas, símbolos y lengua escrita. Toda esta información que interactúa para crear significado a través de la combinación descrita, difícilmente puede ser traducida solo a lengua oral o escrita (Bezemer y Jewitt, 2010).

Si miramos el despliegue del discurso en el aula, estudios acerca de los géneros como configuraciones de significado con un propósito social (Martin y Rose, 2008) nos indican que los estudiantes van aprendiendo distintos géneros a medida que avanzan en la trayectoria escolar, ya que no solo los utilizan para obtener información a través de ellos, sino que en las actividades escolares se les ofrecen oportunidades para ejercitar la producción de dichos patrones de significados (Christie y Derewianka, 2010).

En el modelo estratificado de la Lingüística Sistémico Funcional, la noción de género en un registro particular - como un subpotencial de significado del sistema, en la pendiente de la instanciación - provee de un poder explicativo para la exploración funcional de los textos. Las descripciones de los géneros para el aprendizaje del conocimiento y discurso de las Ciencias Sociales y Naturales en la escuela distinguen entre aquellos géneros con estructura temporal y aquellos sin estructura temporal (Martin y Rose, 2008). Entre los primeros se pueden encontrar, por ejemplo, el relato histórico y aquellos que se relacionan con las formas de actuar en el mundo, como el procedimiento para un experimento o el recuento de un laboratorio. Entre aquellos géneros sin estructura temporal se encuentran los que indican cómo pensar o entender el mundo, como los informes -que en este estudio se han denominado definiciones, para evitar confusiones en la comunidad de profesores - y las explicaciones. Los primeros señalan para los interlocutores las maneras en que los conceptos son, se componen o clasifican, mientras las explicaciones giran en torno a la causalidad o cómo los elementos se relacionan en términos de causa y efecto (Martin y Rose, 2008; Christie y Derewianka, 2010; Manghi, 2013).

Poveda, Morgade y Pulido (2010) investigaron en uno de los géneros de la vida cotidiana: las narraciones literarias infantiles. A partir de la observación de la interacción oral de intérpretes de lengua de señas española interpretando simultáneamente narraciones de cuentacuentos desplegadas mediante la oralidad para una audiencia de niños sordos y oyentes, estos autores postulan el concepto de densidad modal para la suma de medios y modos desplegados en el discurso. La descripción de la situación narrativa permite visibilizar dificultades para los niños sordos para participar en la actividad de cuentacuentos. Los autores explican que asumir que a mayor densidad modal la experiencia narrativa debería ser más comprensible para los niños sordos conlleva un supuesto no explicitado: todos estos modos son decodificables o legibles para los niños y niñas sordos de la audiencia. Además su estudio concluye que muchas de las convenciones empleadas en la combinación del cuentacuentos oyente y la versión del intérprete indican diferencias en las opciones de ambos, por lo que los significados construidos no siempre se encontraban en coherencia produciendo confusión en la audiencia de niños sordos.

En el presente estudio, los discursos que se intercambian, a diferencia de las narraciones en una actividad de cuentacuentos, son, por una parte, científicos, y, por otra, serán evaluados dentro de las prácticas escolares. Por estas razones, los significados pueden volverse muy herméticos si se encuentran alejados de la experiencia de sus estudiantes. Esta dificultad típica del discurso del aula escolar desafía las posibili- 
dades de interacción modal de los recursos seleccionados por los profesores para favorecer el aprendizaje, según los potenciales para significar de cada recurso entretejido en el discurso. Es por este motivo que en este estudio centraremos nuestra mirada principalmente en los recursos que se combinan con la mediación en lengua de señas cara a cara; estos son los medios impresos y tecnológicos.

\section{Metodología}

Esta investigación es parte de un estudio mayor sobre alfabetización semiótica y su mediación en el aula escolar (Fondecyt 1130684). El presente estudio corresponde a dos estudios de caso de clases de Ciencias Sociales y Ciencias Naturales en un centro de educación para personas sordas de la $\vee$ región de Chile. El objetivo es la descripción multimodal de los géneros, medios y modos semióticos utilizados por dos docentes especialistas para mediar el aprendizaje de su grupo de estudiantes sordos de $8^{\circ}$ año básico. Las preguntas que orientan este estudio se relacionan con la comprensión del género definición (report) desde la multimodalidad, así como con las posibilidades de representación y comunicación visual de significados en el aula a partir de él. Para esto es necesaria la descripción contextualizada de los principales medios y modos semióticos. Los medios semióticos serán entendidos como las tecnologías para la representación y comunicación desarrolladas por los seres humanos y su cultura, distinguiendo tres tipos de medios: el medio cara a cara, el medio impreso y el medio electrónico. En una misma situación de comunicación es posible encontrar una orquestación de medios (Kress y otros, 2001), como, por ejemplo, en el aula: interacción cara a cara junto con el uso de medios impresos como pizarrón y cuaderno y/o medios tecnológicos como proyección computacional o software. En cambio, los modos semióticos corresponderán a los recursos para crear significado combinados en cada medio: el habla, la escritura, las fotos, los dibujos, los esquemas, entre otros, cada uno con sus gramáticas distintas (Kress y Van Leeuwen, 1996).

El corpus visual está compuesto por las fotografías de las clases de las unidades curriculares de La Célula para Ciencias Naturales y la RevoIución Industrial para Ciencias Sociales. A partir de la observación del desarrollo de una unidad didáctica en cada una de dichas asignaturas, las notas etnográficas y el registro fotográfico de las clases, se lleva a cabo un análisis multimodal del discurso. Las herramientas heurísticas para explorar el corpus visual corresponden a la teoría del género de la escuela de Sydney para la segmentación de las actividades y la identificación de las estructuras genéricas multimodales que las sustentan; luego el análisis del intercambio de significados, para describir la función de los artefactos semióticos en cuanto a demanda u ofrecimiento de información, bienes o servicios (Halliday, 1982). Para el análisis de los distintos significados construidos visualmente se usan las metafunciones ideacional (representacional) e interpersonal de la propuesta de la Gramática del Diseño Visual de Kress y Van Leeuwen (1996). Para los significados ideacionales los autores distinguen entre imágenes narrativas y conceptuales. Las imágenes narrativas muestran dos objetos o personas vinculados por un proceso de interacción en el cual uno de ellos realiza una acción que recae sobre el otro, mientras que las imágenes conceptuales son representaciones estáticas, sin personas en interacción, y pueden ser de tres tipos: simbólicas, clasificatorias o composicionales. Para el análisis visual de los significados interpersonales los autores proponen distintos parámetros: contacto, distancia social, perspectiva y modalización, para dar cuenta de la relación entre los participantes representados en la imagen y los participantes que interactúan con la imagen.

\section{Hallazgos: las definiciones multimodales}

Entre los hallazgos, en este artículo destacaremos una configuración de significados común a los profesores de este grupo de escolares sor- 
dos observados. Tanto en las clases de Ciencias Sociales como en las de Ciencias Naturales los docentes estructuran sus clases esencialmente en función del género definición o informe (report), que despliegan a partir de un ensamblaje visual: interacción cara a cara mediante el uso de la lengua de señas junto con el uso de la pizarra, presentación computacional, software en línea, cuadernos y guías.

Es importante tener presente dos aspectos que retomaremos a lo largo de este artículo. El primero se refiere al potencial semiótico de los medios y modos que se orquestan en el discurso del aula. Dicho potencial cambia si consideramos los artefactos en sí mismos o si los consideramos en la orquestación cara a cara incluyendo la mediación que realiza el profesor de manera lingüística (Manghi y Cordova, 2011), en este caso mediante lengua de señas también visual. En esta etapa del estudio describiremos el potencial para significar que los medios impresos y tecnológicos ofrecen a los aprendices como artefactos visuales en sí mismos. Estos representan las opciones de los docentes para mostrar visualmente las definiciones que quieren que sus estudiantes aprendan, a través de recursos de carácter estático. Conocer el potencial de significado de estos materiales está directamente vinculado con lo que potencialmente podría aprender un estudiante a partir de ese artefacto y permite vislumbrar las mediaciones necesarias del profesor para hacer accesible el conocimiento y discurso de la disciplina al aprendiz.

El segundo aspecto a considerar tiene que ver con los tipos de definiciones. Según Martin y Rose (2008), los propósitos de la definición (report) en el discurso pedagógico de la ciencia pueden ser tres: construir conocimiento que describe un concepto, conocimiento que clasifica tipos de conceptos o conocimiento que compone o descompone analíticamente partes de un todo (concepto). Estos propósitos definidos para el potencial lingüístico permiten construir tres tipos de definiciones: descriptiva, clasifica- toria y composicional, respectivamente. Esta taxonomía dialoga con la propuesta de la Gramática Visual en relación al potencial semiótico de las imágenes, que pueden ser narrativas y conceptuales. Las imágenes conceptuales son clasificadas por Kress y Van Leeuwen (2001) mediante una tipología similar a las definiciones lingüísticas basadas en la naturaleza visual de la representación de procesos relacionales o existenciales: imágenes simbólicas, analíticas y clasificatorias. Veamos a continuación con más detalle cómo los medios semióticos utilizados por los profesores en las clases con sus estudiantes sordos construyen las definiciones visuales para alfabetizar en cada una de estas disciplinas de este estudio de caso.

\subsection{Definiendo visualmente en Ciencias Naturales}

En Ciencias Naturales, los medios utilizados por el profesor para construir el conocimiento sobre la célula a través de definiciones son artefactos impresos y tecnológicos. Entre los impresos destaca la pizarra y la guía de aprendizaje (fotocopia), los cuales el profesor combina de manera dinámica y contingente con el despliegue de la lengua de señas. En este grupo también podemos incluir el cuaderno como un recurso utilizado por los estudiantes. Por otra parte, los medios tecnológicos usados en estas clases son la presentación computacional (power point) y el software en línea. Ambos son materiales preparados con anticipación - no necesariamente por el profesor, sino solo seleccionados por él-. El primero de ellos es gestionado por el profesor en el despliegue de su interacción cara a cara con los estudiantes y proyectado sobre el pizarrón, en cambio el otro - software- es gestionado de manera autónoma por los escolares en trabajo en parejas frente al computador.

El párrafo anterior corresponde a la descripción del panorama semiótico de los medios utilizados en cinco sesiones de clases, pero interesa además conocer cuál es el potencial para signi- 
ficar de este ensamblaje elegido por el profesor para intercambiar significados acerca del contenido curricular. ¿Qué recursos utiliza el profesor dirigido a sus estudiantes para construir conocimiento sobre la célula? Veamos qué aportan algunos de los artefactos empleados; nos concentraremos en medios impresos prototípicos del aula como el pizarrón y guía y en el medio tecnológico software.

En la mayoría de las clases que desarrollan esta unidad curricular, las definiciones clasificatorias y composicionales son trabajadas por el profesor de una manera multimodal, es decir, a través de la combinación de diferentes modos que interactúan para el proceso de aprendizaje que el profesor propicia para los estudiantes.

\section{FOTO 1}

Guía de aprendizaje, tipos de célula y estructuras

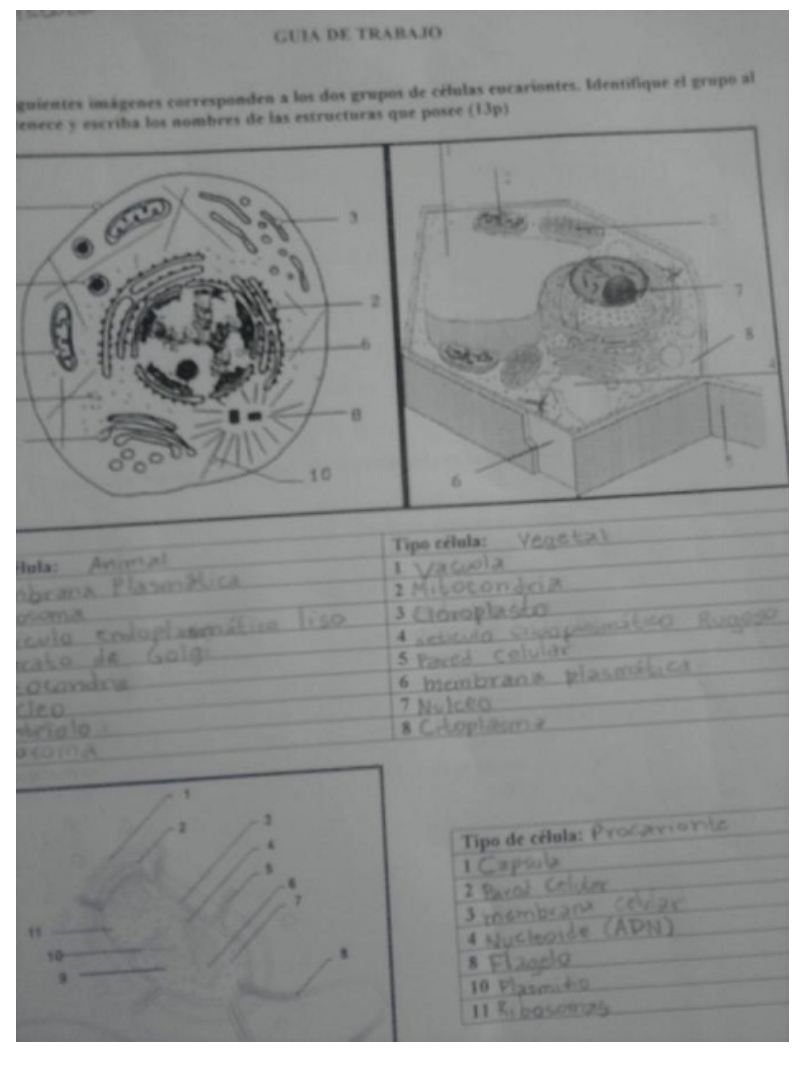

El profesor propone una actividad de intercambio de significados para el aprendizaje a través de una guía a resolver por los estudiantes (ver

\section{FOTO 2}

Actividad en pizarrón

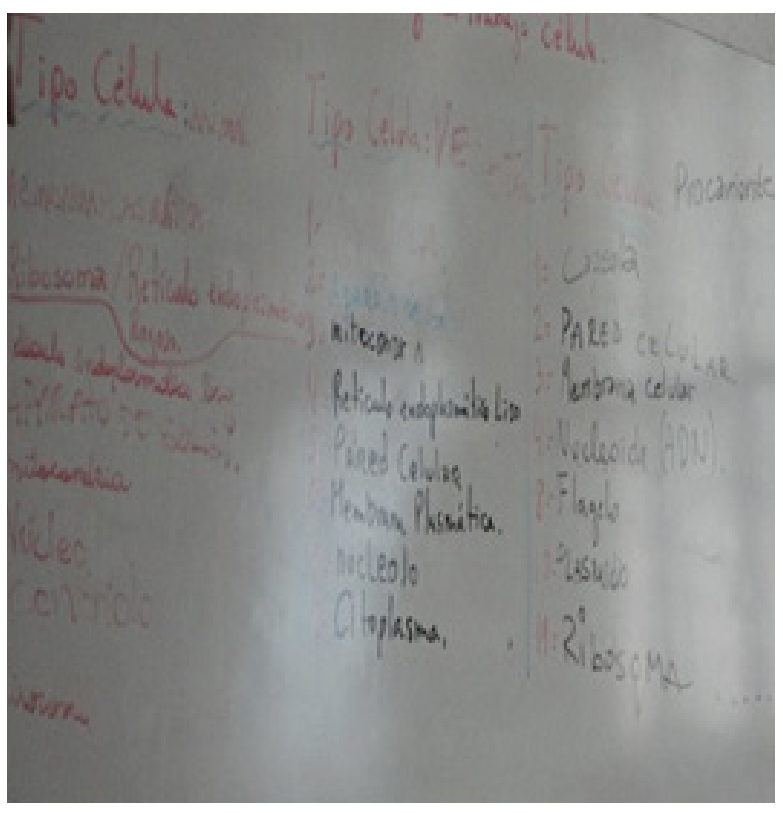

foto 1), que es desarrollada en varias clases. Este es un medio impreso que, en este caso, ensambla instrucciones escritas (demanda de servicios en el intercambio de significados) con tres imágenes conceptuales que ofrecen información espacial. En la disciplina corresponden a dibujos esquemáticos que representan tres modelos consensuados por la biología que generalizan los acuerdos sobre la estructura que compone una unidad (célula animal, vegetal, procarionte). Esta guía les solicita información a los estudiantes a través de números en diferentes partes de las imágenes, y les demanda información escrita a través de números en una tabla vacía. Si miramos el conocimiento disciplinar que este medio busca construir, la guía solicita información a los aprendices sobre tres tipos diferentes de célula: animal, vegetal, procarionte (definición clasificatoria), y para cada una de ellas les pide identificar estructuras morfológicas ubicadas espacialmente en el dibujo esquemático mediante un número, etiquetándolas mediante la escritura en la tabla que lo acompaña (definición composicional). Esta guía permite al estudiante varias oportunidades de aprendizaje. Destacaremos primero 
que la guía le posibilita al aprendiz identificar el tipo de célula tanto en su representación gráfica (dibujo esquemático) como lingüística (escritura), representando la tipología completa en una definición clasificatoria multimodal. Es decir, los tipos de célula no solo tienen un nombre que los diferencia, sino estructuras que también varían en cuanto a formas, tamaños, proporciones, ubicación, etc.

De una manera similar, la guía y su ensamblaje semiótico también favorecen que el estudiante aprenda los nombres escritos de esas estructuras que componen la célula asociando el nombre a la imagen de la estructura, construyendo una definición composicional de naturaleza multimodal. Es lo que Lemke (1998) denomina multiplicación del significado y O'Halloran refiere como expansión semiótica (2011) aludiendo a la combinación de potenciales de significado en un texto multimodal, el cual entrega mucha más información respecto del conocimiento disciplinar que solo el listado de nombres de la estructura en cuestión (ver foto 2). El listado de nombres de las estructuras escrito por los estudiantes en el pizarrón corresponde a una de las actividades de las clases finales observadas. A diferencia del uso de la guía, aquí el profesor usa la pizarra para demandar información a los aprendices a través de los encabezados de un listado para cada uno de los tres tipos de célula. Los estudiantes completan estas tablas mediante la escritura con información aprendida en las tareas anteriores. La tabla restringe la representación de la clasificación y la descomposición de la célula a las etiquetas lingüísticas, omitiendo toda la información espacial. Esta actividad ubicada al final del desarrollo de la unidad curricular ofrece una oportunidad para que los estudiantes se focalicen en los nombres técnicos de los organelos aprendidos.

El profesor combina este medio impreso con el uso de un software computacional del cual los estudiantes deben extraer autónomamente la información que requieren para resolver la guía.
Este medio tecnológico ofrece diversas actividades a los estudiantes, en las cuales se demanda ciertas acciones o servicios: parear o unir conocimientos representados de diferente manera. Si bien hay una consigna escrita en la parte inferior de la pantalla, la acción demandada es difícil de descubrir, por lo que los estudiantes avanzan en la tarea por ensayo y error, ya que desconocen el léxico técnico que aparece escrito, así como las imágenes que también son formas técnicas de representación disciplinar.

En el uso de este medio tecnológico el profesor tiene un rol más pasivo, ya que lo selecciona, propone la actividad y confía en que los estudiantes podrán descubrir lo que se les pide que realicen. Una posibilidad del software para la demanda de servicios se lleva a cabo combinando imagen conceptual y escritura discontinua para solicitar parear partes de un todo. El todo es representado mediante una imagen de un dibujo esquemático, y las partes aparecen indicadas mediante líneas en la imagen y también están representadas de manera escrita en una fila debajo del dibujo (ver foto 3). Los estudiantes deben descubrir cómo etiquetar cada parte del dibujo pareándola con el nombre escrito. Otra posibilidad es que la demanda de servicio se concrete combinando escritura discontinua dispuesta en dos columnas de una tabla. En una columna se ofrecen de manera escrita las etiquetas lingüísticas de las estructuras (mitocondria, ribosoma, etc.), y en la otra columna, las definiciones descriptivas desordenadas (foto 4). El estudiante debe descubrir cómo parear componiendo la definición. El primer tipo de actividad se repite para cada uno de los distintos tipos de célula funcionando como una definición composicional multimodal, mientras que en la segunda actividad, si bien se utiliza una tabla, el conocimiento construido se focaliza en el potencial semiótico lingüístico, por lo que la definición descriptiva es finalmente monomodal.

De esta manera, podemos ver que el panorama semiótico de las clases de Ciencias Naturales 


\section{FOTO 3}

Definición composicional multimodal en software

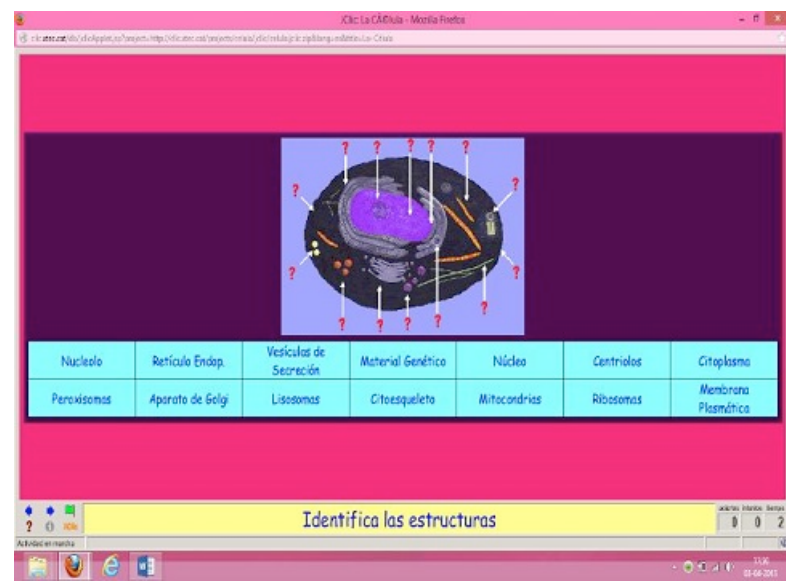

\section{FOTO 4}

Definición descriptiva lingüística en software

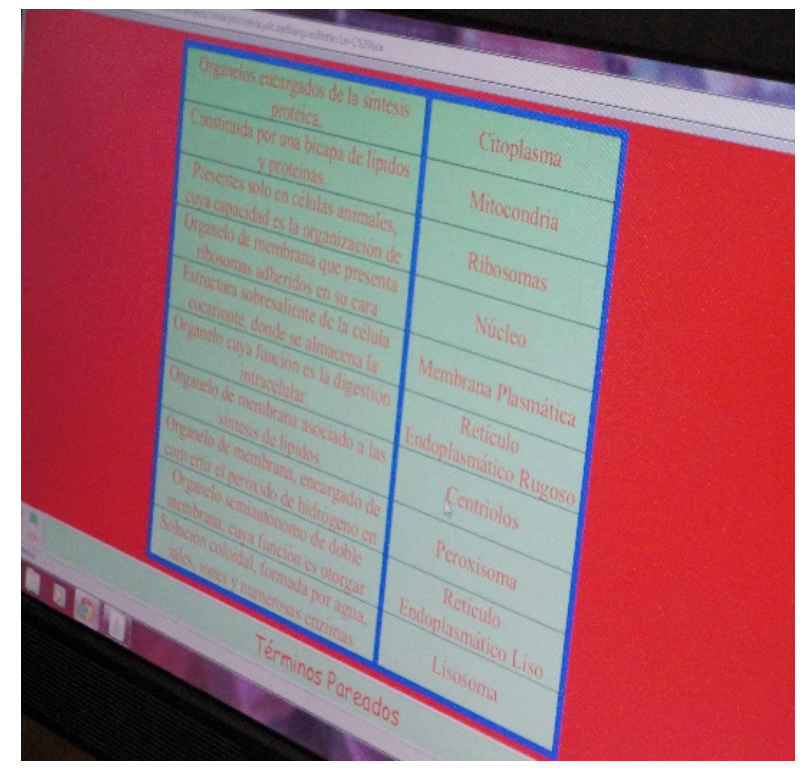

ofrece, por una parte, múltiples conocimientos representados de manera multimodal que pueden favorecer el aprendizaje por parte de estudiantes que acceden a la información de manera visual. Pero, por otra parte, también ofrece importantes desafíos para la semiosis de este grupo de estudiantes sordos debido al alto grado de tecnicismo en imágenes y escritura, así como a su nula relación con el conocimiento más cercano a la experiencia de este grupo de jóvenes.

\subsection{Definiendo visualmente en Ciencias Sociales}

Ahora revisaremos lo que acontece en las clases de Ciencias Sociales para el desarrollo de la unidad Revolución Industrial. Dicha unidad curricular se despliega semióticamente de una manera particular, ya que los medios utilizados por el profesor para construir el conocimiento a través de definiciones corresponden a un único ensamblaje: interacción cara a cara, medio tecnológico y, de manera secundaria, impreso. En este estudio de caso, el profesor desarrolla la totalidad de las clases (cuatro) reutilizando la misma presentación computacional (power point), la cual proyecta sobre el pizarrón. Esto permite que en la medida que despliega la lengua de señas pueda además escribir sobre la imagen proyectada en el pizarrón. Los estudiantes registran las definiciones en sus cuadernos.

El panorama semiótico de esta aula parece ser más homogéneo y reiterativo, pero ¿cuál es el potencial para significar de este ensamblaje elegido por el profesor para intercambiar significados acerca de la Revolución Industrial? ¿Qué modos proyecta en el medio tecnológico para construir conocimiento sobre dicho contenido curricular dirigido a su grupo de estudiantes?

\section{FOTO 5}

Definición descriptiva y clasificatoria

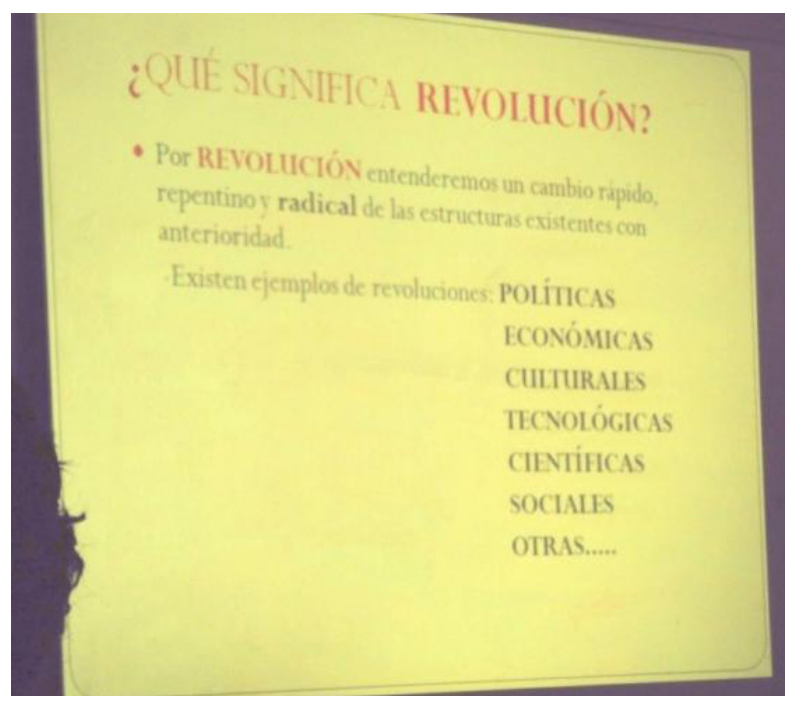




\section{FOTO 6}

Definiciones multimodales en cuadernos

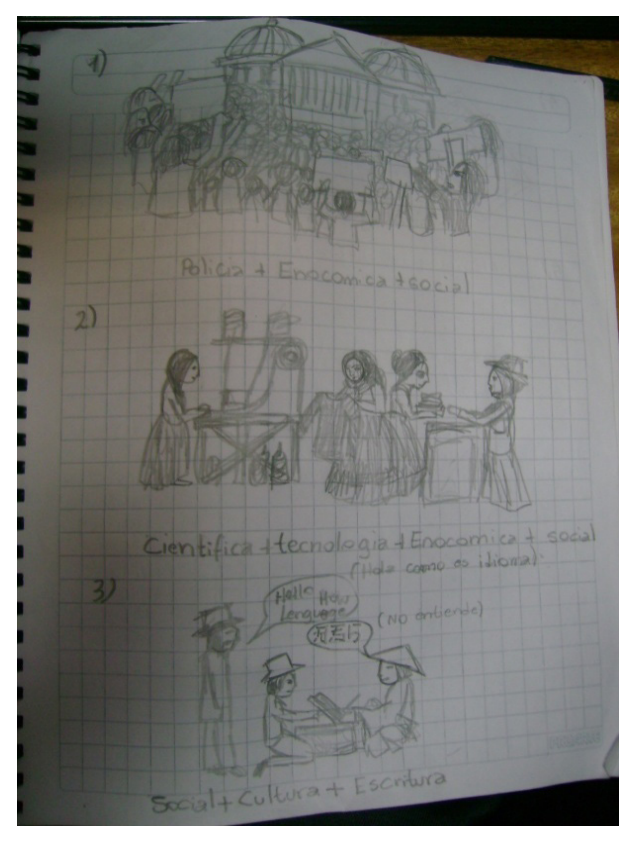

La presentación computacional construida por el profesor reúne diapositivas de distinto tipo. Solo la primera de ellas ofrece información definiendo a través de la escritura el concepto central de la unidad de manera descriptiva y además clasificatoria. Aquí, igual que en biología, la escritura se usa de manera continua para describir los rasgos de una revolución -en función de efectos y tiempo-y de manera discontinua para listar los tipos de revolución (política, económica, cultural, etc.). El resto de las diapositivas retoman —-mediante imágenes - el concepto central trabajado por este profesor: revolución, una nominalización que ofrece una interpretación particular dentro de la disciplina, la cual requiere de pensar desde la causalidad y temporalidad.

Tal como vemos en la foto 6, los estudiantes en una de las sesiones clasifican los tipos de revolución en sus cuadernos recurriendo, según lo solicitado por el profesor, a recursos lingüísticos y visuales. Llaman la atención dos aspectos de esta representación multimodal desarrollada por los aprendices. El primero es que todos los dibujos realizados por los estudiantes no representan nominalizaciones o metáforas gramaticales, sino imágenes narrativas con participantes en acciones, de manera congruente con la experiencia de los aprendices. El segundo elemento es que los dibujos tienen gran cantidad de detalles y recrean lo que el profesor relata mediante lengua de señas y no las imágenes proyectadas, agregando en cada definición la transcripción de las palabras escritas por el profesor en el pizarrón. Dichos dibujos narrativos parecen cumplir la función de desempaquetar los conceptos escritos, bajando el grado de tecnicismo y abstracción.

¿Cómo son las imágenes con las que el profesor define el concepto revolución? El profesor elige distintos tipos de fotos para realzar algunos rasgos del concepto revolución y además definir la Revolución Industrial por contraste con otros tipos de revolución.

Agrupamos las imágenes elegidas por el profesor en dos grupos; el primer grupo corresponde a las imágenes conceptuales. El profesor construye reiteradamente para los aprendices la idea de que la revolución es un cambio radical, ejemplificando con la revolución científica y tecnológica (foto 7 y foto 8). Enfatiza mediante el despliegue de la lengua de señas cara a cara la idea de que algo cambió con cada una de estas revoluciones; desde un punto de vista pedagógico, promueve un pensamiento causal en los estudiantes (algo causó un cambio) mediante el lenguaje. Por su parte, las imágenes no apoyan o ilustran esta forma de pensar de la disciplina, sino que funcionan como imágenes simbólicas. La foto 7 en sí misma constituye una relación de zoom in entre la fotografía microscópica y dos dibujos esquemáticos de estructuras que buscan dar cuenta del cambio producido por este modelo del ADN y la posibilidad de describirlo microscópicamente. La foto 8 muestra diferentes fotos simbólicas de ejemplos de tecnología moderna, para construir un tipo de revolución: la tecnológica. 


\section{FOTO 7}

Imagen revolución científica

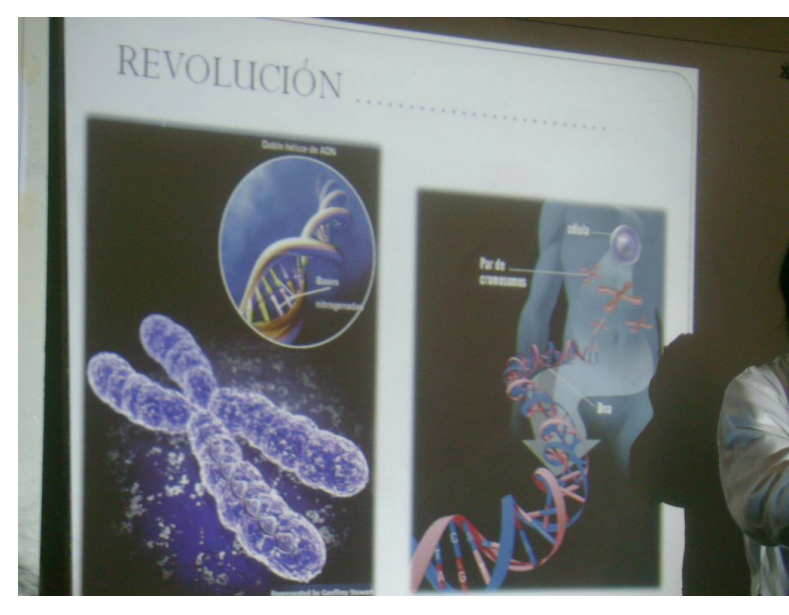

\section{FOTO 8}

Imagen revolución tecnológica

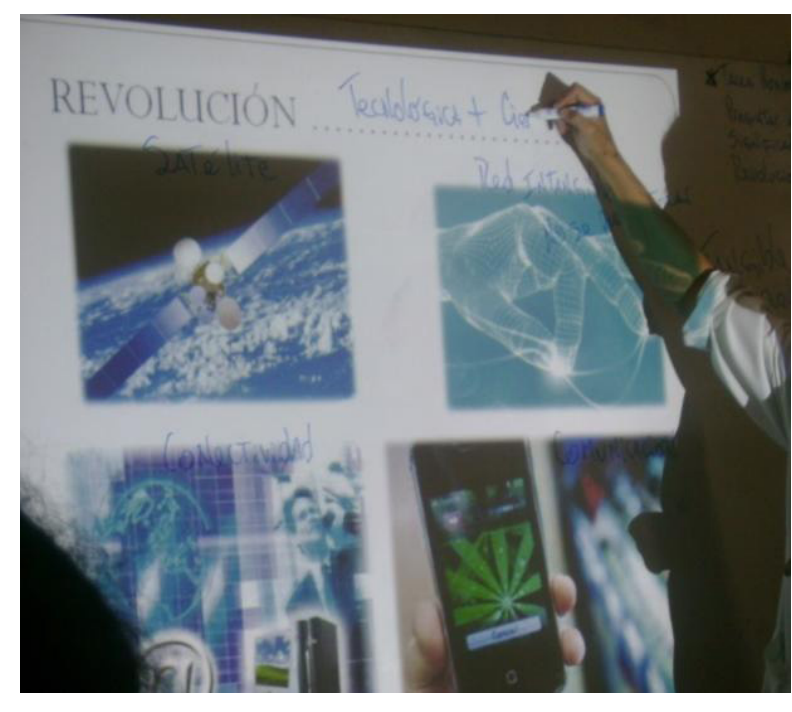

Además estas últimas dos diapositivas incluyen imágenes mediante fotografías, es decir, representaciones reales, lo que funciona como marca de evidencialidad: la revolución que defino ocurrió realmente.

El segundo grupo de imágenes son narrativas. La diferencia con las imágenes conceptuales es que estas representan a una o más personas en acción en alguna circunstancia que es reconocible por los estudiantes. Esta opción hace que el concepto técnico trabajado se relacione con las experiencias cotidianas de los aprendices, haciendo más accesible la taxonomía de la revolución.

Las imágenes narrativas incluyen fotografías y una obra pictórica, que funcionan como fuentes primarias y secundarias respectivamente, nuevamente enfatizando el eje histórico de la evidencialidad. Las primeras dos diapositivas son las fotografías de un hippie y de una manifestación popular (foto 9 y foto 10). La primera muestra una persona sentada en el suelo tocando guitarra. La Gramática del Diseño Visual nos entrega herramientas para poder describir esta narración visual como un ofrecimiento de información. La persona representada se encuentra de frente para ser observada, en un plano medio y de manera horizontal, sin diferencias de poder con el observador y sin ofrecer detalles sobre las emociones del participante representado. Las vestimentas, postura y entorno funcionan como circunstancias que son construidas de manera eficiente por la imagen y entregan información sobre el contexto sociohistórico de una revolución cultural, que difícilmente es posible representar con el lenguaje. Dicha representación visual ofrece un potencial a aprender por los estudiantes, que es mediado lingüísticamente por el profesor destacando cómo la cultura, los valores y las prácticas caracterizaban un tiempo y un espacio.

\section{FOTO 9}

Fotografía narrativa de un hippie

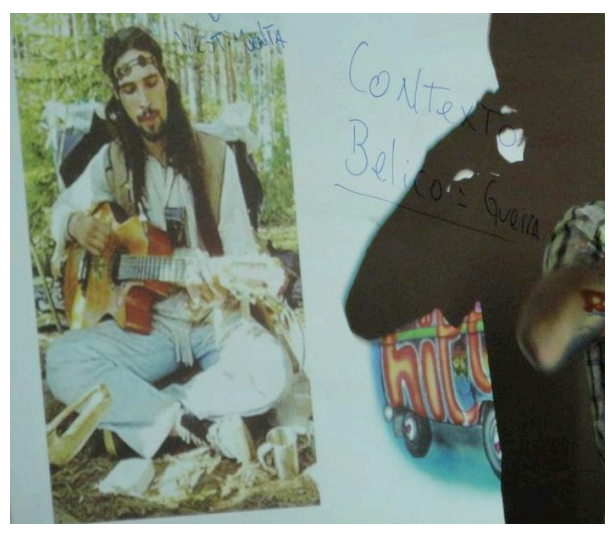




\section{FOTO 10}

Fotografía narrativa manifestación popular

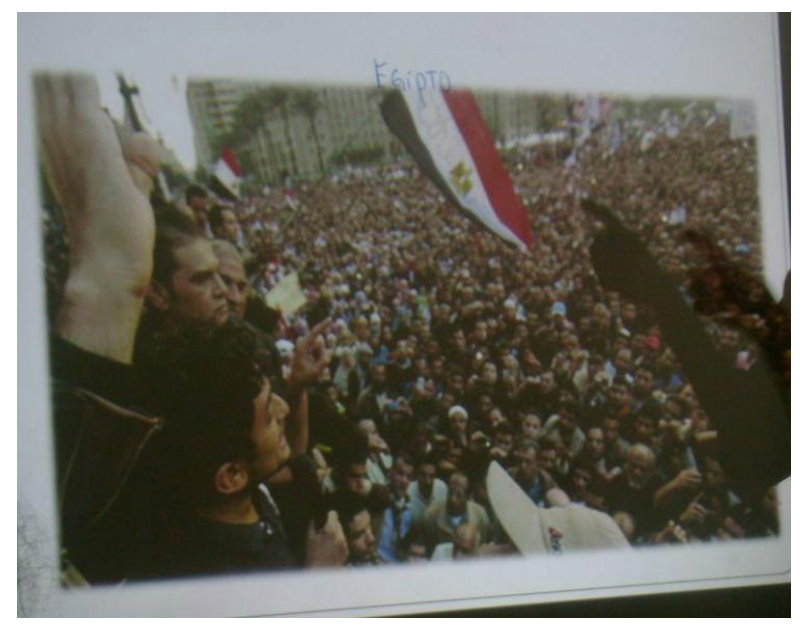

\section{FOTO 11}

Imagen pictórica y fotografía blanco y negro

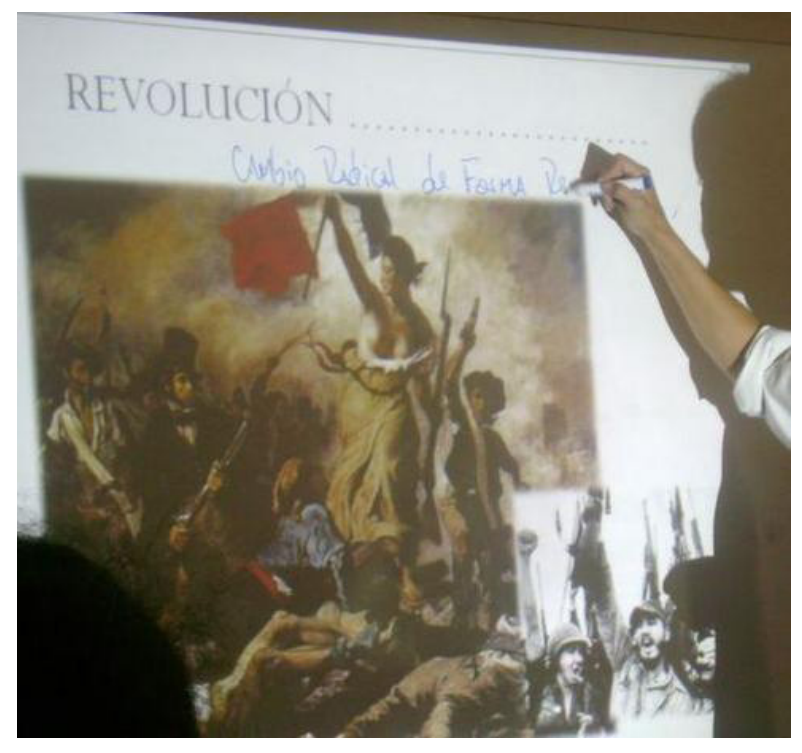

La segunda diapositiva (foto 10) también es una imagen narrativa y nuevamente ofrece información; sin embargo, esta fotografía es diferente, ya que el plano es lejano y el ángulo es vertical, lo que representa imposibilidad de vincularse con las emociones de los participantes y además posiciona al observador en una ubicación más exclusiva, de poder con respecto a la multitud representada más abajo. Esta imagen con diferencias de poder entre los participantes representados alude a la idea de una revolución política. El profesor escribe sobre la proyección identificando la bandera que tiene un lugar importante en la foto con la etiqueta "Egipto", nuevamente mediando, a partir del recurso lingüístico escrito y lengua de señas, la caracterización de una serie de eventos que producen un cambio en un momento histórico y un espacio político particular.

Finalmente, la imagen de una obra pictórica sobre la Revolución francesa (ver foto 11) funciona como fuente secundaria y comparte la diapositiva con una imagen en la esquina inferior, una fotografía en blanco y negro que, como fuente primaria, representa a Che Guevara. La pintura tiene la figura central de una mujer que levanta una bandera; a su alrededor hombres caídos, heridos y hombres de pie alzando sus armas. Las circunstancias nos hablan de un tiempo pasado. Por su parte, la fotografía también replica la idea de un personaje central rodeado de otros, todos uniformados alzando sus armas y puños, esta vez gritando al unísono. Tanto la pintura de época como la fotografía en blanco y negro modalizan la entrega de información dándole veracidad.

Las tres diapositivas construyen visualmente la idea de tipos de revolución, una nominalización que es representada como narración. Esto significa que el profesor desempaqueta este significado mediante la lengua de señas y además mediante las imágenes, haciéndolo congruente con la experiencia de los sujetos y no definiendo el concepto, sino a los protagonistas de la revolución. Los que hacen la revolución, los revolucionarios, son representados como personas que pueden luchar por un cambio a través de la música y la actitud pacífica, a través de las manifestaciones masivas y a través de la lucha armada.

El paisaje semiótico de las clases de Ciencias Sociales nos lleva a los ejes que constituyen el conocimiento histórico. Las fotografías cumplen un papel muy importante en las clases observa- 
das ya que permiten graficar como una narración más cercana al conocimiento cotidiano de los aprendices un tiempo y un espacio que solo pueden ser representados gracias al recurso visual.

\section{Conclusiones}

Las clases observadas desde la óptica de la Semiótica Social permiten hacer visible las diferentes complejidades de los conocimientos y del discurso que cada disciplina escolar ofrece al discurso del aula. La representación y comunicación en las Ciencias Naturales resulta muy compleja y abstracta para este grupo de estudiantes sordos que accede a la información de manera visual, dada la abundancia de clasificaciones y descomposiciones que se deben expresar lingüísticamente y, además, el carácter microscópico de las imágenes, muy alejado de la cotidianeidad. A esto se suma el léxico técnico así como los dibujos técnicos para construir el conocimiento de la célula, lo que ofrece un gran desafío para los estudiantes.

Por otro lado, en las clases de Ciencias Sociales la dificultad parece radicar en conceptualizar la noción central revolución desde los ejes de la disciplina: causalidad, tiempo-espacio y evidencialidad. El pensamiento y el discurso de la historia utilizan léxico que parece de la vida cotidiana pero que aquí se resignifica; este es modelado por el profesor y desplegado mediante ejemplos lingüísticos. Simultáneamente, se enseña a interpretar las fotografías como narraciones visuales que acercan el conocimiento de la historia a la experiencia de los aprendices, desempaquetando las nominalizaciones.

La descripción de estos artefactos nos permite vislumbrar los potenciales de significado de los medios elegidos y la combinación de modos para la representación y comunicación en cada una de las asignaturas. Por ejemplo, en biología, el uso de la guía y del software, que emplean combinaciones de modos semióticos similares, permite definiciones multimodales tanto clasificatorias como composicionales. La diferencia entre el uso de estos dos artefactos es pedagógica, tiene que ver con quien está a cargo de orquestar los significados para los estudiantes y mediar su aprendizaje. La guía es preparada por el profesor, quien realiza constante mediación a los aprendices para su desarrollo; en cambio, el software está prediseñado y es dejado para usarse de manera autónoma por los estudiantes. Para el desarrollo del medio impreso el profesor asume que los estudiantes necesitan de su acción para definir lingüística y visualmente los conceptos aprendidos. En cambio, para el software, el profesor parece alejarse y dejar a los estudiantes descubrir las reglas de navegación y construir intuitivamente los significados técnicos componiendo y clasificando mediante ensayo y error, sin su mediación.

En relación a los medios y su potencial semiótico en historia, a priori podríamos indicar que las fotografías son muy útiles para enseñar. El análisis multimodal del discurso nos señala con más detalle que las fotografías funcionan como evidencia y tienen un importante lugar en las definiciones, ya que desempaquetan las nominalizaciones lingüísticas, construyendo relatos en los que a alguien le ocurre algo en circunstancias sociohistóricas particulares. Esto es susceptible de ser interpretado por los aprendices sordos a partir de la imagen sumada a la mediación del profesor mediante lengua de señas.

Si bien este artículo corresponde a un estudio de caso no generalizable, ya que ha descrito el potencial semiótico de los recursos utilizados contextualizadamente, no se puede asumir que todos los significados construidos visualmente son comprendidos por los estudiantes sordos. El uso de una diversidad de medios y modos de naturaleza visual ofrecería en sí mismo un potencial de aprendizaje a los niños (Kress, 2010), pero coincidimos con Poveda y cols. (2010) en que no necesariamente todos los significados representados serían accesibles a los aprendices. Podríamos decir que, a mayor densidad modal, no nece- 
sariamente es mejor y más fácil la participación de los aprendices en las actividades desarrolladas. En este estudio de caso se pueden reconocer dificultades adicionales. En primer lugar, como en la mayoría de las clases para personas sordas, encontramos un profesor oyente que desarroIla la clase para su curso de estudiantes sordos mediante lengua de señas, que no es su lengua materna. Desarrolla su mediación lo mejor posible, pero seguramente no tiene a su alcance todas las convenciones de la lengua de señas que requiere para expresar los conocimientos de la disciplina. Por eso consideramos muy relevante el rol de los otros medios para la construcción de significado visual. En segundo lugar, las características del discurso pedagógico de la historia o de la biología en sí mismo agregan otra dificultad al aprendizaje. Tal como se indicó, los discursos que se intercambian (tanto lingüístico como visual) son científicos y particulares a cada disciplina, por lo que los significados pueden volverse muy herméticos si se encuentran alejados de la experiencia de los estudiantes.

Por estos motivos, el papel de los profesores resulta fundamental para explotar las características de aprendizaje del grupo de estudiantes y su lógica visual para la comunicación, y los potenciales semióticos de los medios y modos elegidos para significar, articulados con los rasgos epistemológicos de cada disciplina.

\section{Bibliografía citada}

Álvarez, Amelia y Pablo del Rio, 2003: "Educación y Desarrollo: La teoría de Vigotsky y la Zona de Desarrollo Próximo" en César Coll, Jesús Palacios y Alvaro MARCHEsI (comps.): Desarrollo psicológico y educación, tomo Il: Psicología de la educación escolar, Madrid: Alianza, 93-119.

Barletta, Norma y Jorge Mizuno, 2011: "Una propuesta metodológica para la meta reconstrucción histórica" en Teresa Oteiza y Derrin Pinto: (Re) construcción: Discurso, identidad y nación en los manuales escolares de historia y de ciencias sociales, Santiago: Cuarto Propio, 89-128.
Bernstein, Basil, 2000: Pedagogy, Symbolic Control and Identity, Londres: Rowan \& Littlefield.

Bezemer, Jeff y Carey Jewitt, 2010: "Multimodal Analysis: Key Issues" en Lia Litosselitı (ed.): Research Methods in Linguistics, Londres: Continuum, 180-197.

Chevallard, Ives, 1997: La trasposición didáctica: Del saber sabio al saber enseñado, Buenos Aires: Aique.

Christie, Frances, 2002: Classroom Discourse Analysis: A functional perspective, Londres: Continuum.

Christie, Frances y Beverly Derewianka, 2010: School Discourse, Londres: Continuum.

Halliday, Michael, 1982: El lenguaje como semiótica social, México, D. F.: Fondo de Cultura Económica.

Halliday, Michael y James Martin, 1993: Writing science: Literacy and discursive power, Pittsburg: University of Pittsburg

Herrera, Valeria, 2006: "Bases neurológicas del lenguaje hablado y signado", Revista Chilena de Fonoaudiología 7, 2, 59-71.

Hodge, Bob y Gunther Kress, 1988: Social Semiotics, Cambridge: Polity.

Jewitt, Carey, 2011: "The changing pedagogic landscape of subject English in UK classrooms" en Kay O'Halloran y Bradley Smith, Multimodal studies: Exploring issues and domains, Nueva York: Routledge, 184-201.

KRESS, Gunther, 2010: Multimodality: A social semiotic approach to contemporary communication, Londres: Routledge.

KRess, Gunther y Theo van Leeuwen, 1996: Reading Images: The Grammar of Visual Design, Londres: Routledge. 
Kress, Gunther y Theo van LeEuwen, 2001: Multimodal Discourse: The Modes and Media of Contemporary Communication, Londres: Arnold.

Kress, Gunther, Carey Jewitt, Jon Ogborn y Charalampos Tsatsarelis, 2001: Multimodal Teaching and Learning: rhetorics of the science classroom, Londres: Continuum.

Lemke, Jay, 1997: Talking Science: Language, Learning and Values, Barcelona: Paidós.

LemKe, Jay, 1998: "Multiplying meaning: visual and verbal semiotics in scientific text" en James MARTIN y Robert Veel (eds.): Reading Science: critical and functional perspectives on discourses of science, Londres: Routledge, 87-113.

Manghi, Dominique, 2013. "Géneros en la enseñanza escolar: configuraciones de significado en clases de historia y biología desde una perspectiva multimodal" Revista Signos (46) 82, 236-247.

Manghi, Dominique y Juan Pablo Cordova, 2011: "Definiciones y explicaciones multimodales: Potencial semiótico en la enseñanza de la biología en Educación Media”, Logos: Revista de Lingüística, Filosofía y Literatura 21 (2), 17-39.

MarTin, James, 2003: "Making history, grammar for interpretation" en James MARTIN y Ruth WODAK (eds.): Re/reading the past: critical and functional perspectives on time and value, Amsterdam: Benjamin, 19-57.

Martin, James, 2013: "Embedded literacy: Knowledge as meaning", Linguistics and Education 24, 23-37.

MarTin, James y David Rose, 2008: Genre relations: mapping culture, Londres: Equinox.

Martin, James, Karl Maton y Erika Matruglio, 2010: "Historical cosmologies: Epistemology and axiology in Australian secondary school history discourse", Revista Signos 43 (74), 433-463.

Maton, Karl, 2013: "Making semantic waves: A key to cumulative knowledge-building”, Linguistics and Education 24, 8-22.

Mercer, Neil, 2010: "Interactive whiteboards and classroom interactions", Better: Evidence-based Education, Autumn issue, 8-9.

Moss, Gillian y Diana Chamorro, 2011: "La enseñanza de las ciencias sin asidero en el tiempo ni el espacio: Análisis del discurso de dos textos escolares" en Norma BARletta y Diana Chamorro (eds.): Texto escolar y aprendizaje, Barranquilla: Universidad del Norte, 123-148.

Morano, Estela, 2010: "Aportes del análisis de género y discurso a los procesos de enseñanza y aprendizaje escolar: las ciencias biológicas y la historia", Discurso y Sociedad 4 (2), 294-331.

New London Group, 1996: "A Pedagogy of Multiliteracities: Designing Social Futures”, Harvard Educational Review 66 (1), 60-92.

O'Halloran, Kay, 2011: "Multimodal Discourse Analysis" en Ken Hyland and Brian Paltridge (eds.): Companion to Discourse Analysis, Londres: Continuum, 120-137.

Oteiza, Teresa, 2009: "Diálogo entre textos e imágenes: análisis multimodal de textos escolares desde una perspectiva intertextual", Delta 25, 657-664.

Oteiza, Teresa, 2011: "Representación de las memorias del pasado: intersubjetividad en el discurso pedagógico de la historia" en Teresa Oteiza y Derrin Pinto (eds.): En (re)construcción: Discurso, identidad y nación en los manuales escolares de historia y de ciencias sociales, Santiago: Cuarto Propio, 129-172.

Palacios, Agustina, 2008: El modelo social de discapacidad: orígenes, caracterización y plasmación en la Convención Internacional sobre los Derechos de las Personas con Discapacidad, Madrid: cinca.

Poveda, David, Marta Morgade y Laura Pulido, 2010: "Multimodalidad y participación de la infancia 
sorda en contextos de socialización literaria informal", AIBR 5 (1), 126-151.

Rogoff, Barbara, 1990: Apprenticeship in thinking. Cognitive development in social context, Oxford: Oxford University Press.

Schleppegrell, Mary, 2004: The language of schooling. A Functional Linguistics Perspective, Nueva Jersey: Lawrence Erlbaum Associates.

Van Leeuwen, Theo, 2005: Introducing Social Semiotics, Londres: Routledge.

Veel, Robert, 1997: "Learning how to meanscientifically speaking: apprenticeship into scientific discourse in the secondary school" en Frances Christie y James Martin (eds.): Genre and Institutions: social processes in the workplace and school, Londres: Painter, 160-194. 